(2) Open Access Full Text Article

\title{
Intravitreal aflibercept versus intravitreal ranibizumab for the treatment of diabetic macular edema
}

This article was published in the following Dove Press journal:

Clinical Ophthalmology

23 March 2017

Number of times this article has been viewed

\author{
Sameh Mosaad Fouda \\ Ahmed M Bahgat \\ Department of Ophthalmology, \\ Faculty of Medicine, Zagazig \\ University, Zagazig, Egypt
}

Purpose: The purpose of this study was to compare the efficacy of intravitreal aflibercept and ranibizumab in the treatment of diabetic macular edema (DME) in eyes with moderate visual loss.

Patients and methods: This study is a randomized prospective study. Seventy eyes with DME were divided into two groups (each containing 35 eyes). Eyes in group I were treated with intravitreal injection of $2 \mathrm{mg} / 0.05 \mathrm{~mL}$ aflibercept and eyes in group II were treated with intravitreal injection of $0.5 \mathrm{mg} / 0.1 \mathrm{~mL}$ ranibizumab. All the eyes had three successive injections as a loading dose (with 1 month interval), and then the patients were followed up monthly for 12 months. The outcomes of the study were visual acuity, central macular thickness (CMT), and the number of re-injections of the drug.

Results: Mean age of the patients in group I was 55.05 \pm 4.7 years and in group II was $56.64 \pm 5.8$ years $(P=0.17)$. The mean baseline best corrected visual acuity (BCVA) of eyes treated with aflibercept was $0.17 \pm 0.05$ and with ranibizumab was $0.18 \pm 0.04(P=0.9)$. BCVA was improved in both the groups at the end of the follow-up period and was found to be $0.42 \pm 0.28$ and $0.37 \pm 0.23$, respectively $(P=0.27)$. The mean baseline CMT of eyes in group I was $465.29 \pm 33.7 \mu \mathrm{m}$ and in group II was $471.5 \pm 34.4 \mu \mathrm{m}(P=0.65)$. CMT decreased in both the groups to $360.8 \pm 85.7 \mu \mathrm{m}$ and $387.3 \pm 87.8 \mu \mathrm{m}$, respectively $(P=0.2)$. The mean number of drug re-injection was $2.62 \pm 0.68$ and $3.03 \pm 0.95$ in both the groups, respectively $(P=0.02)$.

Conclusion: Aflibercept and ranibizumab have the same efficacy in the treatment of DME in eyes with moderate visual loss but with less number of drug re-injection and less treatment burden with aflibercept $(2.62 \pm 0.68$ versus $3.03 \pm 0.95)$.

Keywords: aflibercept, ranibizumab, diabetic macular edema, intravitreal injection

\section{Introduction}

Diabetic macular edema (DME) is one of the manifestations of diabetic retinopathy, which has an impact on central visual acuity. It is considered the main cause of visual loss and impairment in eyes with diabetic retinopathy. ${ }^{1,2}$

DME is characterized by the presence of exudation and accumulation of extracellular fluid in the retinal layers, which are caused by increase in the permeability of retinal blood vessels. Vascular endothelial growth factor (VEGF) is associated with the breakdown of the blood-retinal barrier, causing increased vascular permeability that results in the pathogenesis and development of macular edema. ${ }^{3,4}$

VEGF is a protein that promotes the angiogenesis and increases the vascular permeability. VEGF is a main cause of vascular growth and edema, which are present in many vascular retinal disorders such as diabetic retinopathy and DME. 5,6
Correspondence: Sameh Mosaad Fouda Department of Ophthalmology, Faculty of Medicine, Zagazig University, Zagazig University Street, Zagazig, Egypt, 44519 Tel +20 I 28492 I290

Email samehfouda2006@yahoo.com $\mathrm{BY}$
he for commercial use of this work, please see paragraphs 4.2 and 5 of our Terms (https://www.dovepress.com/terms.php). 
Many studies showed that the inhibition of VEGF with intravitreal injection of anti-VEGF agents is helpful in the treatment of DME. ${ }^{7}$ There are three commonly used intravitreal anti-VEGF agents: aflibercept, bevacizumab, and ranibizumab. They are beneficial and safe for the treatment of DME. Only ranibizumab and aflibercept are approved by the Food and Drug Administration (FDA) for this indication. ${ }^{8-10}$

Ranibizumab is a recombinant humanized monoclonal antibody fragment that binds to all the isoforms of human VEGF-A. Intravitreal ranibizumab reduces DME with subsequent visual improvement, thus it replaced laser photocoagulation in the treatment of DME..$^{11,12}$

Aflibercept is a recombinant fusion protein that binds all isoforms of VEGF-A, VEGF-B, and placental growth factor. The drug is currently approved for the treatment of neovascular age-related macular degeneration, macular edema associated with vein occlusion, and DME. ${ }^{13,14}$ It was shown to be more effective than ranibizumab and bevacizumab in regaining lost visual acuity in a large randomized controlled trial. ${ }^{15}$

The aim of this study is to compare intravitreal aflibercept and ranibizumab for the treatment of DME in eyes with moderate visual loss.

\section{Patients and methods}

A total of 70 eyes of 42 diabetic patients were included in this prospective randomized study. The study was approved by the ethical committee of the Mitghamr Lasik and Eye Center (approval number 212015), and all patients provided written informed consent to participate according to the tenets of the Declaration of Helsinki. The patients were randomly divided into two groups; patients in group I (35 eyes) were treated with intravitreal aflibercept injection and patients in group II ( 35 eyes) were treated with intravitreal ranibizumab injection.

\section{Inclusion criteria}

Patients with type I or II diabetes, DME in eyes as diagnosed clinically and with OCT, patients with best corrected visual acuity (BCVA) ranged from 0.1 to 0.25 (moderate visual loss) and with edema affecting the central $1 \mathrm{~mm}$ of the macula (detected with optical coherence tomography) were included in this study.

\section{Exclusion criteria}

Eyes with vascular retinal disorders other than diabetic retinopathy (eg, choroidal neovascularization), eyes that received previous intravitreal injection of any agents, eyes with previous intraocular surgery or with previous laser treatment were excluded from the study. Eyes with proliferative diabetic retinopathy were also excluded. Eyes with BCVA $<0.1$ or $>0.25$ were excluded; also eyes with edema not affecting the central $1 \mathrm{~mm}$ were excluded from the study.

\section{Ophthalmic examination}

Complete ophthalmic examination was done for all patients including measurement of BCVA, IOP measurement, slit lamp examination, and dilated fundus examination. Macular examination with Heidelberg Spectralis-OCT (Heidelberg Engineering, Heidelberg, Germany) was done for all eyes. Macular thickness map with follow-up software was used to detect and measure the changes in central macular thickness (CMT).

\section{Procedure for intravitreal injection}

The anti-VEGF agents were injected into the eyes in both the groups at baseline and then every 1 month for three intravitreal injections as a loading dose. Anti-VEGF was re-injected if the macular edema was persistent or if the visual acuity or the CMT worsened.

All eyes in group I received an injection of $2 \mathrm{mg} / 0.05 \mathrm{~mL}$ aflibercept (Eylea; Regeneron Pharmaceuticals, NY, USA) and those in group II received an injection of $0.5 \mathrm{mg} / 0.1 \mathrm{~mL}$ ranibizumab (Lucentis; Genentech, USA, Inc., San Francisco, CA, USA). Topical anesthesia was induced by $0.4 \%$ Benoxinate eye drops before injection. After disinfection, draping, and proper topical anesthesia, the anti-VEGF agent was injected into the vitreous cavity. A 27-gauge needle was used in intravitreal injection, which was done at $4 \mathrm{~mm}$ from the limbs if the patient was phakic and at $3.5 \mathrm{~mm}$ if the patient was pseudophakic. Evaluation of vision was done at the end of the maneuver to ensure that the intraocular pressure was not excessively high.

\section{Follow-up and outcome}

All eyes were examined monthly for 12 months after the last injection of the loading dose. BCVA and CMT were recorded at baseline and follow-up visits. The number of re-injections (not including the loading dose injections) was calculated and reported in each group.

The collected data were analyzed statistically using nonpaired $t$-test in Statistical Package for the Social Sciences (SPSS) (IBM SPSS Statistics 14.0; Chicago, IL, USA). $P<0.05$ was considered statistically significant. The 1 st, 3rd, 6th, and 12th month follow-up visits were the benchmark visits, and the results of examination at these visits were used in the tables and figures to make results easier to comprehend. 


\section{Results}

A total of 70 eyes of 42 patients received intraocular injections of aflibercept (group I, 35 eyes) or intraocular injections of ranibizumab (group II, 35 eyes). The mean age of the patients was $55.05 \pm 4.7$ years (range: $45-65$ years) in aflibercept group and $56.64 \pm 5.8$ years (range: $42-68$ years) in ranibizumab group. No significant difference was detected between the two groups $(P=0.17)$.

The mean baseline BCVA and CMT of eyes treated with aflibercept were $0.17 \pm 0.05 \mu \mathrm{m}$ and $465.29 \pm 33.7 \mu \mathrm{m}$ and of eyes treated with ranibizumab were $0.18 \pm 0.04 \mu \mathrm{m}$ and $471.5 \pm 34.4 \mu \mathrm{m}$, respectively. These differences were not statistically significant ( $P=0.9$ and 0.65 , respectively).

The BCVA was recorded monthly for 1 year after the last loading injection. At the end of the follow-up period, the mean BCVA in eyes treated with aflibercept improved to $0.42 \pm 0.28$ and that in eyes treated with ranibizumab improved to $0.37 \pm 0.23$ with no significant difference between the two groups $(P=0.27)$ (Table 1 and Figure 1). At the end of follow-up period, eyes in aflibercept group (35 eyes) showed improvement of vision in 22 eyes $(62.9 \%)$, vision was worsened in 7 eyes $(20 \%)$, and remained stationary in 6 eyes $(17.1 \%)$. Eyes in ranibizumab group (35 eyes) showed vision improvement in 20 eyes (57.1\%), worsening vision in 7 eyes $(20 \%)$, and stationary vision in 8 eyes $(22.9 \%)$ (Figure 2$)$.

The CMT was measured at every visit during the follow-up period. At the end of the follow-up period, the mean CMT in eyes of group I (aflibercept) decreased to $360.8 \pm 85.7 \mu \mathrm{m}$, whereas in eyes of group II (ranibizumab), the mean CMT decreased to $387.3 \pm 87.8 \mu \mathrm{m}$ with no significant difference between the two groups $(P=0.2)$ (Table 2 and Figure 3). The number of dry eyes (with no macular edema) at the end of the study was $25(71 \%)$ in the aflibercept group and $23(66 \%)$ in the ranibizumab group.

The drugs were injected into the study eyes at baseline and then every 1 month until the 3rd month (loading dose of three injections). During the follow-up period, the drug re-injection was considered on monthly basis if the macular edema

Table I Best corrected visual acuity (measured by Snellen decimal notation) at baseline and at benchmark follow-up visits in both the groups

\begin{tabular}{llllll}
\hline & Baseline & $\begin{array}{l}\text { Ist } \\
\text { month }\end{array}$ & $\begin{array}{l}\text { 3rd } \\
\text { month }\end{array}$ & $\begin{array}{l}\text { 6th } \\
\text { month }\end{array}$ & $\begin{array}{l}\text { I2th } \\
\text { month }\end{array}$ \\
\hline Aflibercept & $0.17 \pm 0.05$ & $0.39 \pm 0.21$ & $0.35 \pm 0.2$ & $0.37 \pm 0.24$ & $0.42 \pm 0.28$ \\
group & $(0.1-0.25)$ & $(0.1-0.7)$ & $(0.05-0.7)$ & $(0.2-0.8)$ & $(0.1-0.8)$ \\
Ranibizumab & $0.18 \pm 0.04$ & $0.34 \pm 0.19$ & $0.33 \pm 0.19$ & $0.41 \pm 0.19$ & $0.37 \pm 0.23$ \\
group & $(0.1-0.3)$ & $(0.1-0.7)$ & $(0.1-0.6)$ & $(0.05-0.7)$ & $(0.05-0.7)$ \\
$P$-value & 0.9 & 0.83 & 0.7 & 0.87 & 0.27 \\
\hline
\end{tabular}

Note: The data in this table are presented as mean \pm SD (range).

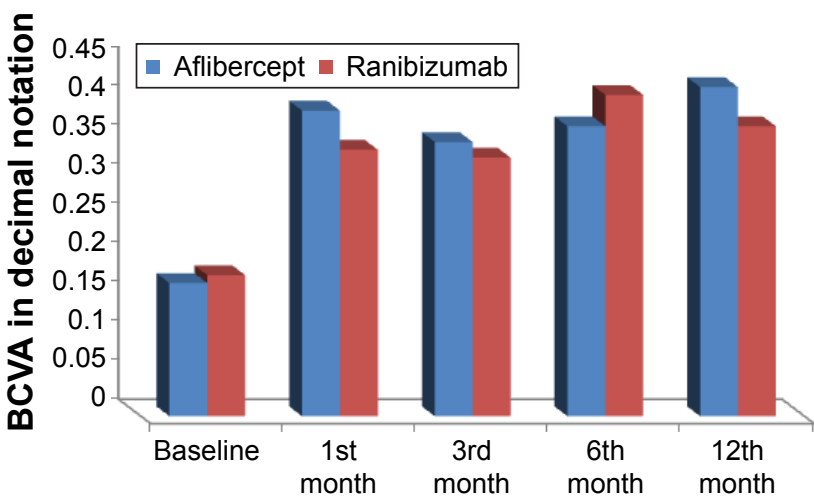

Figure I Baseline and follow-up best corrected visual acuity (BCVA) measured in both the groups.

persisted or worsened in comparison with the preceding visit and if visual acuity worsened in comparison with the preceding visit. The treatment was withheld if there was no change of macular thickness or visual acuity for two successive visits but was reinstated once vision or macular edema worsened again. Improvement or worsening of macular edema was defined as a $10 \%$ change of CMT in comparison with last visit while 0.1 change of visual acuity in comparison with last visit was considered a significant change. The number of injections in group I (aflibercept) ranged from 2 to 5 times with an average of $2.62 \pm 0.68$, whereas for eyes in group II, the number of ranibizumab re-injections ranged from 2 to 6 times with an average of $3.03 \pm 0.95$. These results were significantly different $(P=0.02)$.

No serious complications such as retinal detachment or endophthalmitis were detected in any patient of both the groups during the follow-up period.

\section{Discussion}

DME is caused by excessive retinal vascular permeability, resulting in increase in retinal thickness with leakage of fluid and plasma constituents. ${ }^{16}$ VEGF is associated with the breakdown of the blood-retinal barrier, which may be the cause of increased retinal vascular permeability that results

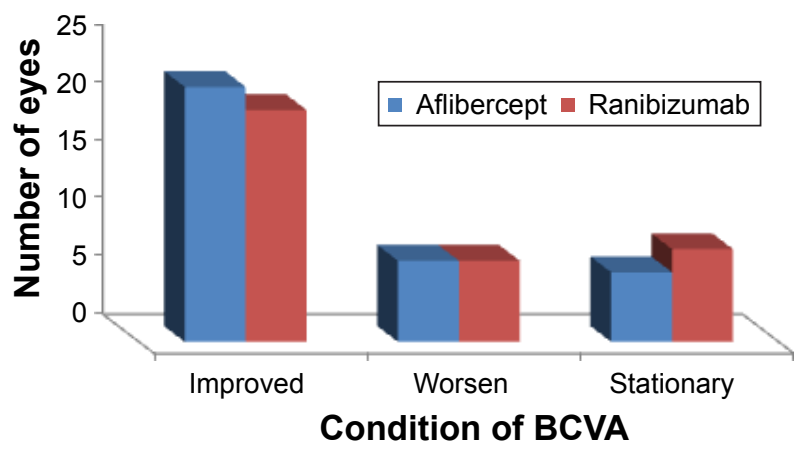

Figure 2 Changes in best corrected visual acuity (BCVA) in eyes of both the groups of the study. 
Table 2 Central macular thickness (measured in $\mu \mathrm{m}$ ) at baseline and at benchmark follow-up visits in both the groups

\begin{tabular}{llllll}
\hline & Baseline & Ist month & 3rd month & 6th month & I 2th month \\
\hline Aflibercept group & $465.29 \pm 33.7$ & $365.4 \pm 72.2$ & $370.54 \pm 83.6$ & $39 I .7 \pm 85.8$ & $360.8 \pm 85.7$ \\
& $(4 I I-535)$ & $(256-499)$ & $(250-527)$ & $(245-536)$ & $(265-50 I)$ \\
Ranibizumab group & $47 I .5 \pm 34.4$ & $388.06 \pm 77.3$ & $394.3 \pm 84.8$ & $360.1 \pm 74.4$ & $387.3 \pm 87.8$ \\
& $(402-516)$ & $(245-519)$ & $(246-578)$ & $(236-529)$ & $(253-522)$ \\
$P$-value & 0.65 & 0.2 & 0.24 & 0.1 & 0.2 \\
\hline
\end{tabular}

Note: The data in this table are presented as mean \pm SD (range).

in retinal and macular edema. Many studies have found elevated levels of VEGF in ocular fluids of patients with diabetic retinopathy and in eyes with DME. ${ }^{17,18}$

The development of VEGF inhibitors (anti-VEGF) has revolutionized DME treatment with an improvement in visual acuity. ${ }^{19}$ Although ranibizumab is a Fab fragment of a monoclonal anti-VEGF, aflibercept is a recent anti-VEGF agent made of a recombinant fusion protein that binds both VEGF isoforms $\mathrm{A}$ and $\mathrm{B}$, and placental growth factor. ${ }^{20}$ This study compares intravitreal aflibercept and ranibizumab in the treatment of SME in eyes with moderate visual loss.

Aflibercept has a longer half-life in eye than ranibizumab, and it binds VEGF and placental growth factor as well. This may explain the lesser treatment burden of intravitreal aflibercept recorded in this study.

In this study, only one eye in the aflibercept group and none in the ranibizumab group had no injections in the first 3 months after the initial three loading doses. This may suggest that a loading dose of three intravitreal injections may not be enough in those eyes. In protocol $\mathrm{T},{ }^{15}$ there was no loading doses, and the treatment was given monthly as needed from the start, but the number of injections in the first 6 months was comparable. Many studies proved the efficacy and safety of ranibizumab intravitreal injection in the treatment of DME. ${ }^{21,22}$

Wells et a ${ }^{15}$ studied the effect of aflibercept, bevacizumab, and ranibizumab for DME. They concluded that the relative effect of these drugs depended on baseline visual

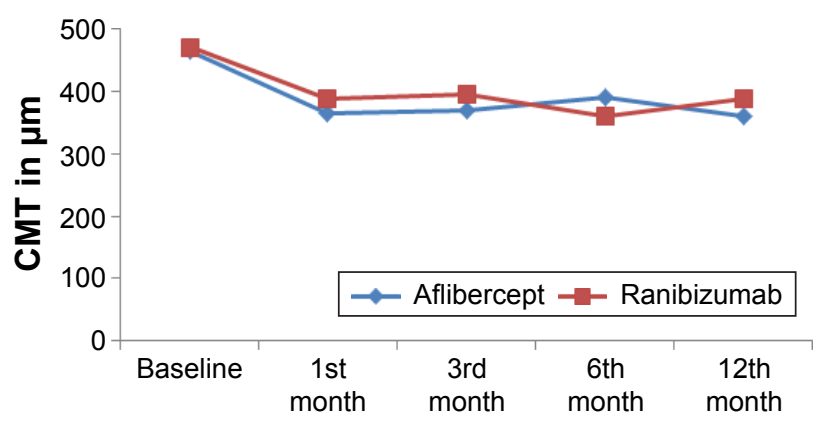

Figure 3 Baseline and follow-up central macular thickness (CMT) measured in both the groups. acuity. When the initial visual acuity loss was mild, there were no apparent differences, on average, among the study groups. At worse levels of initial visual acuity, aflibercept was more effective at improving vision. In the present study, the baseline visual acuity was between 0.25 and 0.1 , which is a common presenting visual acuity in parts of the world without a tight diabetic retinopathy screening program. In those eyes, other studies ${ }^{15,23}$ showed that aflibercept was superior to bevacizumab and ranibizumab regrading visual gain. At the end of the follow-up period, this study failed to show significant difference in BCVA between aflibercept and ranibizumab $(P=0.27)$ but showed less treatment burden with aflibercept. This could be explained by smaller sample size.

CMT is measured in all eyes in this study. The baseline CMT in both the groups did not differ significantly, and the results indicated that both aflibercept and ranibizumab showed the same degree of CMT decrease at the end of the follow-up time ( $P=0.2)$.

All eyes in this study were injected with anti-VEGF agents with the loading dose of three injections (with 1 month interval), then during the follow-up period, the anti-VEGF was re-injected when the macular edema was still present. The mean number of aflibercept was $2.62 \pm 0.68$ and that of ranibizumab was $3.03 \pm 0.95$ with significant difference between the two drugs $(P=0.02)$.

\section{Conclusion}

Both aflibercept and ranibizumab improve visual acuity and decrease CMT in eyes with DME and moderate visual loss with no difference between the two drugs, whereas aflibercept needs a number of re-injections less than that of ranibizumab (2.62 \pm 0.68 versus $3.03 \pm 0.95)$.

\section{Compliance with ethical standards}

All procedures performed in studies involving human participants were in accordance with the ethical standards of the institutional and/or national research committee and with the 1964 Helsinki declaration and its later amendments or comparable ethical standards. 


\section{Disclosure}

The authors report no conflicts of interest in this work.

\section{References}

1. Abràmoff MD, Lou $\mathrm{Y}$, Erginay $\mathrm{A}$, et al. Improved automated detection of diabetic retinopathy on a publicly available dataset through integration of deep learning. Invest Ophthalmol Vis Sci. 2016;57:5200-5206.

2. Holekamp NM. Overview of diabetic macular edema. Am J Manag Care. 2016;22:284-291

3. Dugel PU, Hillenkamp J, Sivaprasad S, et al. Baseline visual acuity strongly predicts visual acuity gain in patients with diabetic macular edema following anti-vascular endothelial growth factor treatment across trials. Clin Ophthalmol. 2016;10:1103-1110.

4. Shah CP, Heier JS. Aflibercept for diabetic macular edema in eyes previously treated with ranibizumab and/or bevacizumab may further improve macular thickness. Ophthalmic Surg Lasers Imaging Retina. 2016;47:836-839.

5. Ishida $\mathrm{S}$, Usui T, Yamashiro K, et al. VEGF164 is proinflammatory in the diabetic retina. Invest Ophthalmol Vis Sci. 2003;44:2155-2162.

6. Ross EL, Hutton DW, Stein JD, Bressler NM, Jampol LM, Glassman AR. Cost-effectiveness of aflibercept, bevacizumab, and ranibizumab for diabetic macular edema treatment: analysis from the diabetic retinopathy clinical research network comparative effectiveness trial. JAMA Ophthalmol. 2016;134:888-896.

7. Călugăru D, Călugăru M. Conversion to aflibercept after prior antiVEGF therapy for persistent diabetic macular edema. Am JOphthalmol. 2016;168:290-291.

8. Shah SU, Harless A, Bleau L, Maturi RK. Prospective randomized subject-masked study of intravitreal bevacizumab monotherapy versus dexamethasone implant monotherapy in the treatment of persistent diabetic macular edema. Retina. 2016;36:1986-1996.

9. Nguyen QD, Brown DM, Marcus DM, et al. Ranibizumab for diabetic macular edema: results from 2 phase III randomized trials: RISE and RIDE. Ophthalmology. 2012;119:789-801.

10. Nguyen QD, Shah SM, Khwaja AA, et al. Two-year outcomes of the ranibizumab for edema of the macula in diabetes (READ-2) study. Ophthalmology. 2010;117:2146-2151.

11. Scott IU, Edwards AR, Beck RW, et al. A phase II randomized clinical trial of intravitreal bevacizumab for diabetic macular edema. Ophthalmology. 2007;114:1860-1867.
12. Korobelnik JF, Do DV, Schmidt-Erfurth U, et al. Intravitreal aflibercept for diabetic macular edema. Ophthalmology. 2014;121:2247-2254.

13. Mitchell P, Bandello F, Schmidt EU, et al. The RESTORE study: ranibizumab monotherapy or combined with laser versus laser monotherapy for diabetic macular edema. Ophthalmology. 2011;118:615-625.

14. Ishibashi T, Li X, Koh A, et al. The REVEAL study: ranibizumab monotherapy or combined with laser versus laser monotherapy in Asian patients with diabetic macular edema. Ophthalmology. 2015;122: 1402-1415.

15. Wells JA, Glassman AR, Ayala AR, et al. Aflibercept, bevacizumab, or ranibizumab for diabetic macular edema. $N$ Engl J Med. 2015;13: 1193-1203.

16. Dugel PU, Hillenkamp J, Sivaprasad S, et al. Baseline visual acuity strongly predicts visual acuity gain in patients with diabetic macular edema following anti-vascular endothelial growth factor treatment across trials. Clin Ophthalmol. 2016;10:1103-1110.

17. Watanabe D, Suzuma K, Suzuma I, et al. Vitreous levels of angiopoietin 2 and vascular endothelial growth factor in patients with proliferative diabetic retinopathy. Am J Ophthalmol. 2005;139:476-481.

18. Adamis AP, Miller JW, Bernal MT, et al. Increased vascular endothelial growth factor levels in the vitreous of eyes with proliferative diabetic retinopathy. Am J Ophthalmol. 1994;118(4):445-450.

19. Bandello F, Cicinelli MV, Parodi MB. Anti-VEGF molecules for the management of diabetic macular edema. Curr Pharm Des. 2015;21: $4731-4737$.

20. Calvo CM, Sridhar J, Shahlaee A, Ho AC. Reduction of diabetic macular edema in the untreated fellow eye following intravitreal injection of aflibercept. Ophthalmic Surg Lasers Imaging Retina. 2016;47: 474-476.

21. Egan C, Zhu H, Lee A, et al. The United Kingdom Diabetic Retinopathy Electronic Medical Record Users Group, Report 1: baseline characteristics and visual acuity outcomes in eyes treated with intravitreal injections of ranibizumab for diabetic macular oedema. Br J Ophthalmol. 2017; 101(1):75-80.

22. Nguyen QD, Shah SM, Khwaja AA, et al. Two-year outcomes of the ranibizumab for edema of the macula in diabetes (READ-2) study. Ophthalmology. 2010;117:2146-2151.

23. Heier JS, Bressler NM, Avery RL, et al. Comparison of aflibercept, bevacizumab and ranibizumab for treatment of diabetic macular edema: extrapolation of data to clinical practice. JAMA Ophthalmol. 2016;134:959
Clinical Ophthalmology

\section{Publish your work in this journal}

Clinical Ophthalmology is an international, peer-reviewed journal covering all subspecialties within ophthalmology. Key topics include: Optometry; Visual science; Pharmacology and drug therapy in eye diseases; Basic Sciences; Primary and Secondary eye care; Patient Safety and Quality of Care Improvements. This journal is indexed on

\section{Dovepress}

PubMed Central and CAS, and is the official journal of The Society of Clinical Ophthalmology (SCO). The manuscript management system is completely online and includes a very quick and fair peer-review system, which is all easy to use. Visit http://www.dovepress.com/ testimonials.php to read real quotes from published authors. 